\title{
Influence of photoperiod and water supply on production of seed and dry matter in three varieties of soybean, Glycine max (L.) Merr.
}

\author{
O. Aquino ${ }^{1}$ and G. F. Makkink ${ }^{2}$ \\ 1 Centro de Investigaciones Agronómicas, Maracay, Venezuela \\ 2 Institute for Biological and Chemical Research on Field Crops and Herbage, \\ Wageningen, the Netherlands
}

Received: 7 April 1971

\begin{abstract}
Summary
The relationships between seed production and dry matter production, and between dry matter production and water consumption were studied for 3 varieties of soybean under two daylength regimes in a greenhouse experiment. Separately the photosynthetic rate was determined under 4 light intensities. No significant differences were found between the varieties 'Pennsoy', 'L.Z.' and 'Improved Pelican'. The main results are shown in Fig. 1-5.
\end{abstract}

\section{Introduction}

A field experiment with three varieties of soybean under irrigation was carried out at Maracay, Venezuela, during the years 1965, 1966 and 1967. To obtain a background for interpretation an additional greenhouse experiment was conducted. This was set up to study seed and dry matter production in dependence on water supply at two photoperiods. This experiment was conducted at the Institute for Biological and Chemical Research on Field Crops and Herbage at Wageningen, the Netherlands.

\section{Materials and methods}

The varieties 'Improved Pelican', 'L.Z.' and 'Pennsoy' were grown in pots (diameter $20 \mathrm{~cm}$, height $20 \mathrm{~cm}$ ) in a greenhouse. The controlled temperatures were $30^{\circ} \mathrm{C}$ by day and $20^{\circ} \mathrm{C}$ during the night. Small pebbles on top of the soil prevented evaporation.

Each pot was fertilized once with the following mixture: $12 \mathrm{~g}$ of $\mathrm{Ca}\left(\mathrm{H}_{2} \mathrm{PO}_{4}\right)_{2}$ with $18 \% \mathrm{P}, 8 \mathrm{~g}$ of $\mathrm{K}_{2} \mathrm{SO}_{4}$ with $26 \% \mathrm{~K}, 6 \mathrm{~g}$ of $\mathrm{CaCO}_{3}$ and $2 \mathrm{~g}$ of $\mathrm{NH}_{4} \mathrm{NO}_{3}$ with $36 \% \mathrm{~N}$.

The prevailing photoperiod in the months July, August and September averaged 16.2, 14.2 and 12.7 hours, respectively; the controlled photoperiod of 12 hours was from 8 a.m. until 8 p.m. and was obtained by shielding the plants with black curtains during the other hours of the day and the night.

In the 1968 experiment (from 25 June till 21 September) 3 varieties with 2 water treatments and 3 replicates were placed in a block; 2 of these blocks were placed 
under the prevailing day length, the other two under the 8-hour day regime. One water treatment was optimum (the pots were placed in shallow containers with a sheet of water). The others received a water application of $200 \mathrm{~cm}^{3}$ per pot each time at the first signs of wilting. The pots were weighed regularly. In order to determine the water consumption under optimum water conditions, one of the replicates stood in a shallow one-pot container with a cover around the pot to prevent evaporation of the water. This container was weighed. After a weekly turn all the 3 replicates were placed in the container to avoid continuous poor aeration.

The 1969 experiment was carried out (from 27 June till 23 September) according to a statistically improved arrangement. The same 3 varieties with four water treatments formed blocks; 3 replicates under the prevailing day length were placed at random between the other 3 under the 12-hour day regime. The 4 water treatments received $1 / 4,2 / 4,3 / 4$ or $4 / 4$ of a standard water application.

In addition to the greenhouse experiment rates of photosynthesis and transpiration were determined under different light intensities in the laboratory. The compartment in which these investigations take place permits automatical recording of four separate plants simultaneously (van Oorschot and Belksma, 1961; Louwerse and van Oorschot, 1969). The experiments were made with one full-grown leaf not severed from the plant or with a complete plant of 20 days under different light intensities. The three varieties were cultivated on Hoagland solutions, diluted $1: 1$.

\section{Results}

In 1968 and 1969 the plants did not flower in the prevailing day length (more than 12 hours of daylight) and continued developing leaves only. Seed production (S) in controlled day length ( 8 a.m. -8 p.m.) showed a linear relationship with dry matter production (DM ; seeds included, roots not harvested; see Fig. 1). Results of the 1969 experiment were :

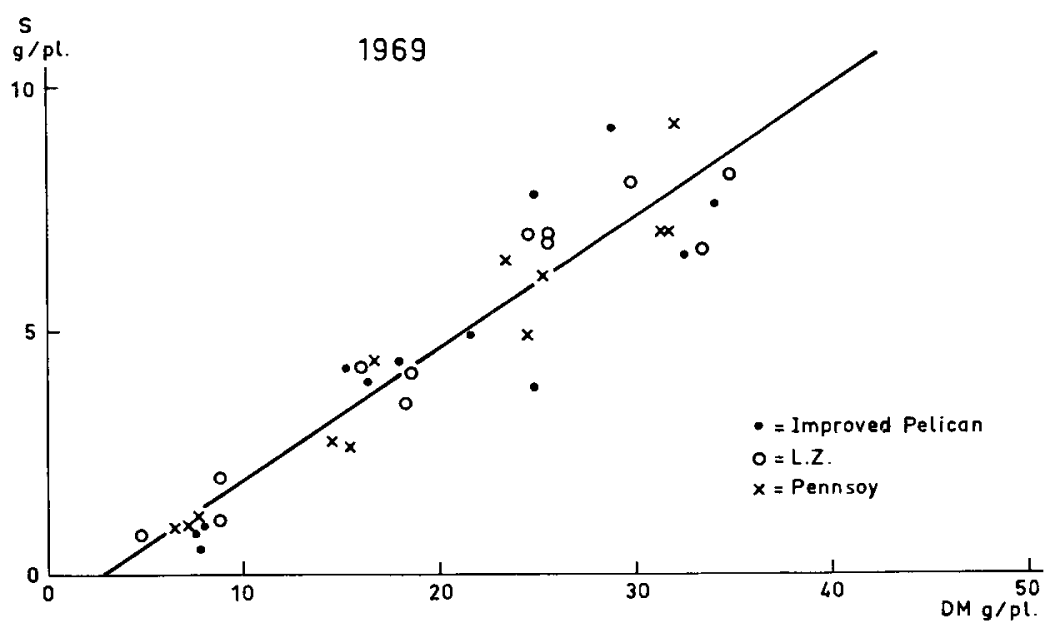

Fig. 1. Seed production ( $\mathrm{g} /$ plant) as a function of total dry matter production (seed incl. roots not). 
Table 1. Seed production (dry) (g/plant) of three varieties under 4 water supply treatments (1969).

\begin{tabular}{lccccc}
\hline Variety & \multicolumn{5}{l}{ Water supply } \\
\cline { 2 - 6 } & $1 / 4$ & $2 / 4$ & $3 / 4$ & $4 / 4$ & average \\
I.P. & 0.87 & 4.17 & 5.50 & 7.73 & 4.56 \\
L.Z. & 1.30 & 3.93 & 6.87 & 7.60 & 4.92 \\
P. & 1.07 & 3.23 & 5.80 & 7.73 & 4.45 \\
Average & 1.08 & 3.78 & 6.05 & 7.69 & 4.65 \\
\hline
\end{tabular}

$\begin{array}{ll}\text { 'Improved Pelican' } & S=0.272( \pm 0.042) . \mathrm{DM}-0.858( \pm 0.920) \mathrm{g} / \mathrm{plant} \\ \text { 'L.Z.' } & \mathrm{S}=0.259( \pm 0.025) . \mathrm{DM}-0.425( \pm 0.569) \mathrm{g} / \mathrm{plant} \\ \text { 'Pennsoy' } & \mathrm{S}=0.276( \pm 0.023) . \mathrm{DM}-0.985( \pm 0.509) \mathrm{g} / \mathrm{plant}\end{array}$

The standard deviations (between brackets) show that differences between the varieties are not significant. It is not quite certain whether the regression line passes through the origin or not. An analysis of variance shows that in 1969 dry weight of seeds was positively affected $(\mathrm{P} \% \leqslant 0.1)$ by water supply, but not by variety or the interaction of water supply and variety (in both cases $\mathrm{P} \%>25$ ) (Table 1).

Production of dry matter DM (without roots; g/plant) is linearly related with water consumption $\mathrm{W}(\mathrm{kg} / \mathrm{plant}$; Fig. 2$)$. The regression equations in controlled day length are:

'Improved Pelican': $\mathrm{DM}=2.63( \pm 0.140) . \mathrm{W}-3.22( \pm 1.32)$

'L.Z.' $\quad: \quad \mathrm{DM}=2.76( \pm 0.161) . \mathrm{W}-3.69( \pm 1.51)$

'Pennsoy' $\quad: \mathrm{DM}=2.75( \pm 0.075) . \mathrm{W}-4.60( \pm 0.71)$

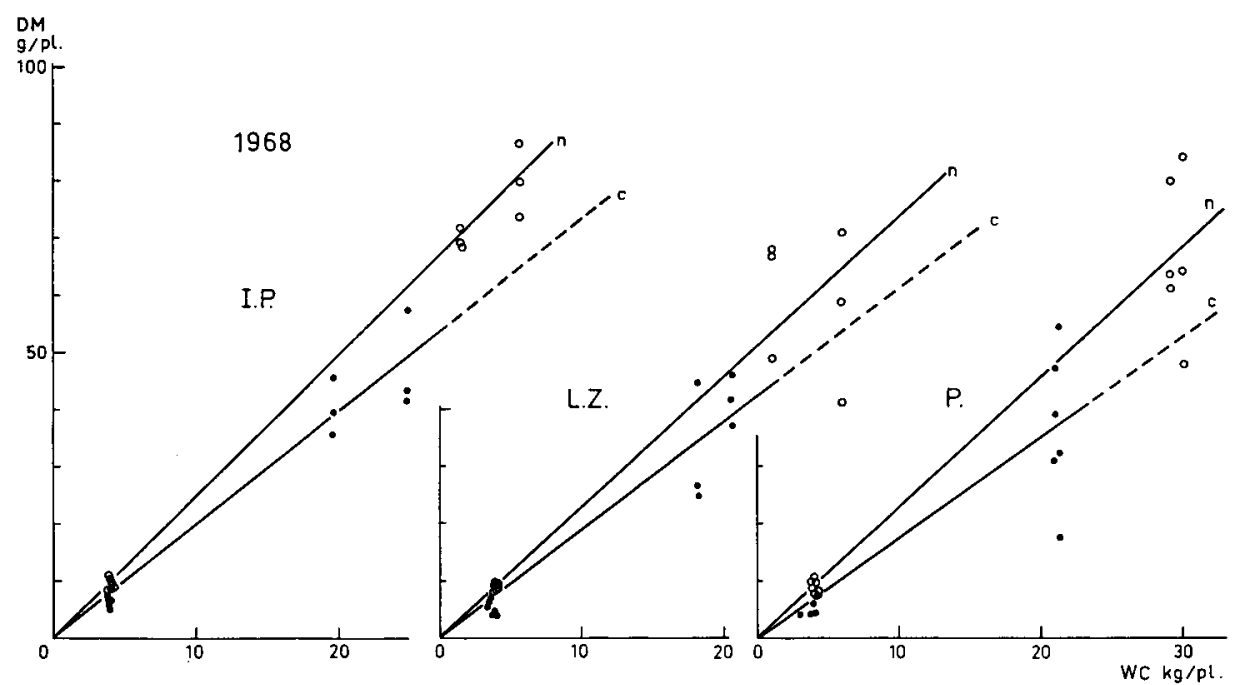

Fig. 2. Total dry matter production (g/plant) as a function of water consumption (kg/plant) for each variety in $1968 ; \mathrm{n}=$ prevailing daylength; $\mathrm{c}=$ controlled daylength. The lines, drawn by hand through the origin, show the consistent differences. 
and in prevailing day length:

'Improved Pelican': $\mathrm{DM}=2.88( \pm 0.124) . \mathrm{W}-2.57( \pm 1.12)$

'L.Z.' $\quad: \mathrm{DM}=3.13( \pm 0.093) . \mathrm{W}-4.68( \pm 0.84)$

'Pennsoy' $\quad: \mathrm{DM}=3.08( \pm 0.168) . \mathrm{W}-4.28( \pm 1.51)$

There are no significant differences between the varieties. The overall equations for controlled and prevailing day length, respectively show significantly differing coefficients :

Table 2. Dry weight (seed included, roots not) (g/plant) for water treatments, day lengths and varieties.

\begin{tabular}{|c|c|c|c|c|c|}
\hline \multirow[t]{2}{*}{ Day length } & \multicolumn{5}{|c|}{ Water supply } \\
\hline & $1 / 4$ & $2 / 4$ & $3 / 4$ & $4 / 4$ & average \\
\hline $\begin{array}{l}\text { Prevailing } \\
\text { Controlled }\end{array}$ & $\begin{array}{l}7.65 \\
7.42\end{array}$ & $\begin{array}{l}17.13 \\
16.52\end{array}$ & $\begin{array}{l}26.64 \\
24.40\end{array}$ & $\begin{array}{l}34.51 \\
31.97\end{array}$ & $\begin{array}{l}21.4 \\
20.0\end{array}$ \\
\hline \multirow[t]{3}{*}{ Average } & 7.53 & 16.8 & 25.5 & 33.2 & 20.7 \\
\hline & \multicolumn{5}{|c|}{ Varieties } \\
\hline & I.P. & L.Z. & & P. & average \\
\hline $\begin{array}{l}\text { Prevailing } \\
\text { Controlled }\end{array}$ & $\begin{array}{l}21.6 \\
19.9\end{array}$ & $\begin{array}{l}21.5 \\
20.6\end{array}$ & & $\begin{array}{l}21.4 \\
19.7\end{array}$ & $\begin{array}{l}21.4 \\
20.0\end{array}$ \\
\hline $\begin{array}{rr}\text { Water } & 1 \\
2 \\
3 \\
4\end{array}$ & $\begin{array}{r}8.1 \\
16.7 \\
25.5 \\
32.7\end{array}$ & $\begin{array}{r}7.6 \\
17.1 \\
25.4 \\
34.2\end{array}$ & & $\begin{array}{r}6.9 \\
16.7 \\
25.6 \\
32.9\end{array}$ & $\begin{array}{r}7.5 \\
16.8 \\
25.5 \\
33.2\end{array}$ \\
\hline Average & 20.7 & 21.1 & & 20.5 & 20.7 \\
\hline
\end{tabular}

Table 3. Water consumption ( $\mathrm{kg} / \mathrm{plant}$ ) for water treatments, day lengths and varieties.

\begin{tabular}{|c|c|c|c|c|c|}
\hline \multirow[t]{2}{*}{ Day length } & \multicolumn{5}{|c|}{ Water supply } \\
\hline & $1 / 4$ & $2 / 4$ & $3 / 4$ & $4 / 4$ & average \\
\hline Prevailing & 3.87 & 6.90 & 9.83 & 12.80 & 8.35 \\
\hline Controlled & 4.30 & 7.32 & 10.31 & 13.31 & 8.81 \\
\hline \multirow[t]{3}{*}{ Average } & 4.08 & 7.11 & 10.07 & 13.05 & 5.58 \\
\hline & \multicolumn{5}{|c|}{ Varieties } \\
\hline & I.P. & L.Z. & & P. & average \\
\hline $\begin{array}{l}\text { Prevailing } \\
\text { Controlled }\end{array}$ & $\begin{array}{l}8.36 \\
8.80\end{array}$ & $\begin{array}{l}8.35 \\
8.81\end{array}$ & & $\begin{array}{l}8.34 \\
8.83\end{array}$ & $\begin{array}{l}8.35 \\
8.81\end{array}$ \\
\hline $\begin{array}{r}\text { Water } 1 \\
2 \\
3 \\
4\end{array}$ & $\begin{array}{r}4.10 \\
7.09 \\
10.05 \\
13.07\end{array}$ & $\begin{array}{r}4.08 \\
7.12 \\
10.08 \\
13.04\end{array}$ & & $\begin{array}{r}4.09 \\
7.13 \\
10.06 \\
13.05\end{array}$ & $\begin{array}{r}4.08 \\
7.11 \\
10.06 \\
13.05\end{array}$ \\
\hline Average & 8.58 & 8.58 & & 8.58 & 8.58 \\
\hline
\end{tabular}




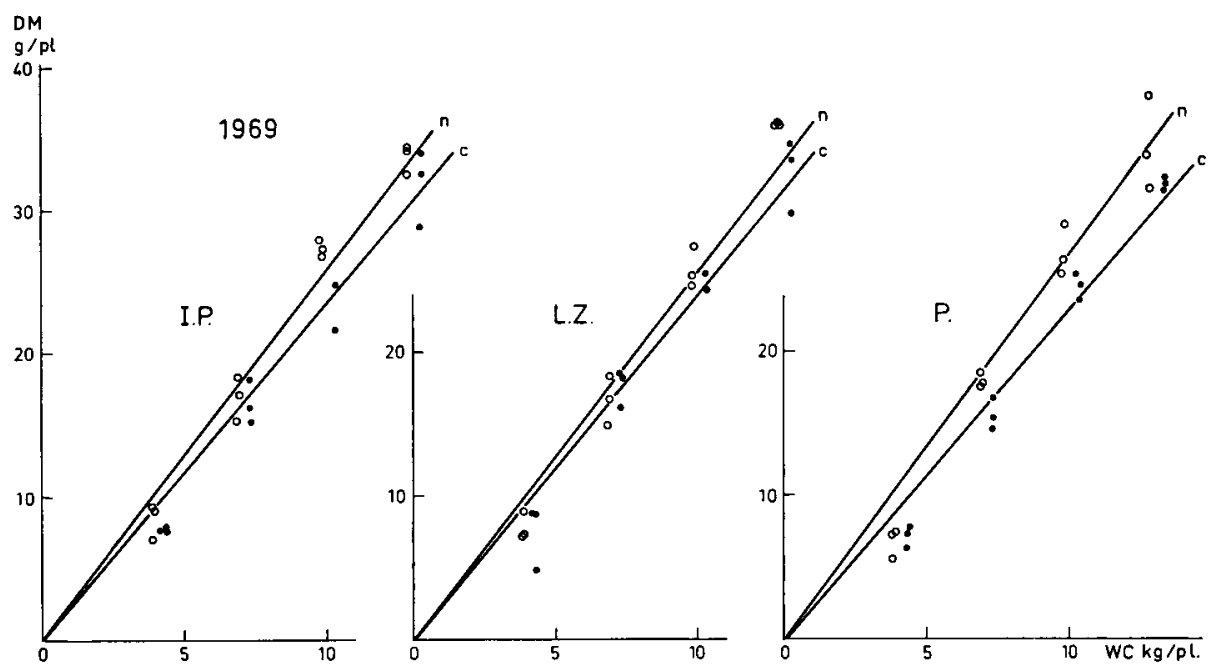

Fig. 3. As Fig. 2, for 1969.

controlled day length: $\mathrm{DM}=2.71( \pm 0.0749) . \mathrm{W}-3.83( \pm 0.707)$ prevailing day length : $\mathrm{DM}=3.03( \pm 0.0741) . \mathrm{W}-3.84( \pm 0.666)$

The analysis of variance shows that in 1969 dry weight of plants (Table 2) showed a significant increase under influence of water supply (P\% $\%$, the effect of day length regime and its interaction with water supply was rather uncertain ( $\mathrm{P} \% 5-10)$.

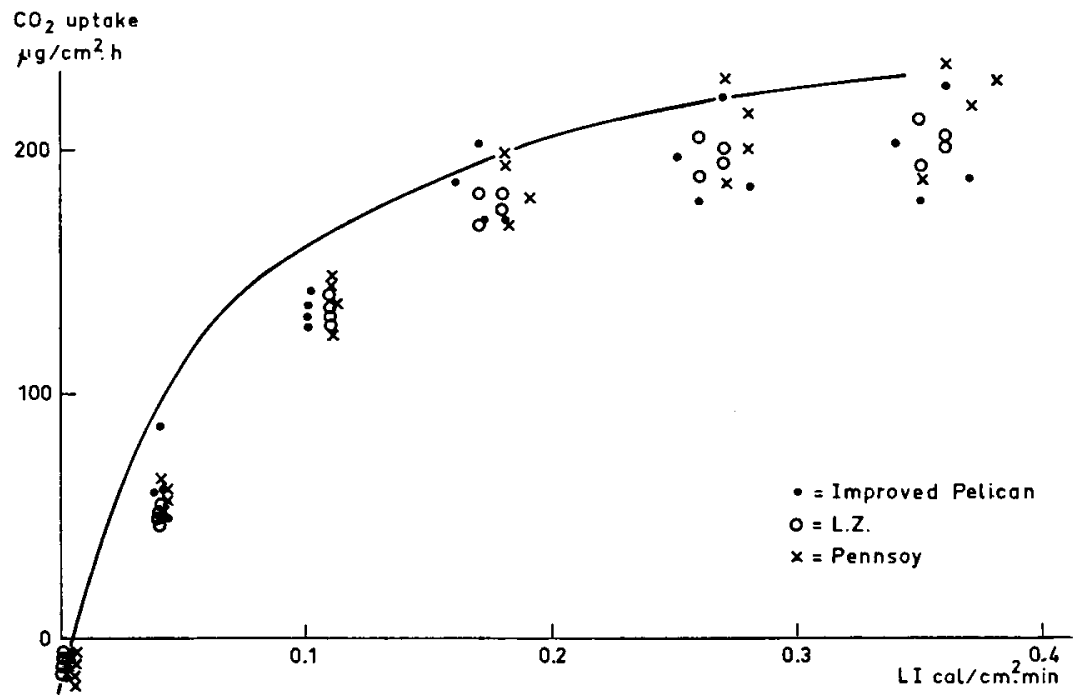

Fig. 4. Photosynthesis rate $\left(\mathrm{CO}_{2}\right.$ uptake, $\left.\mu \mathrm{g} / \mathrm{cm}^{2} . \mathrm{h}\right)$ as a function of lig.it intensity (cal $\left./ \mathrm{cm}^{2} . \mathrm{min}\right)$. The curve is taken from de Wit (1966), average for a number of agricultural plant species. 


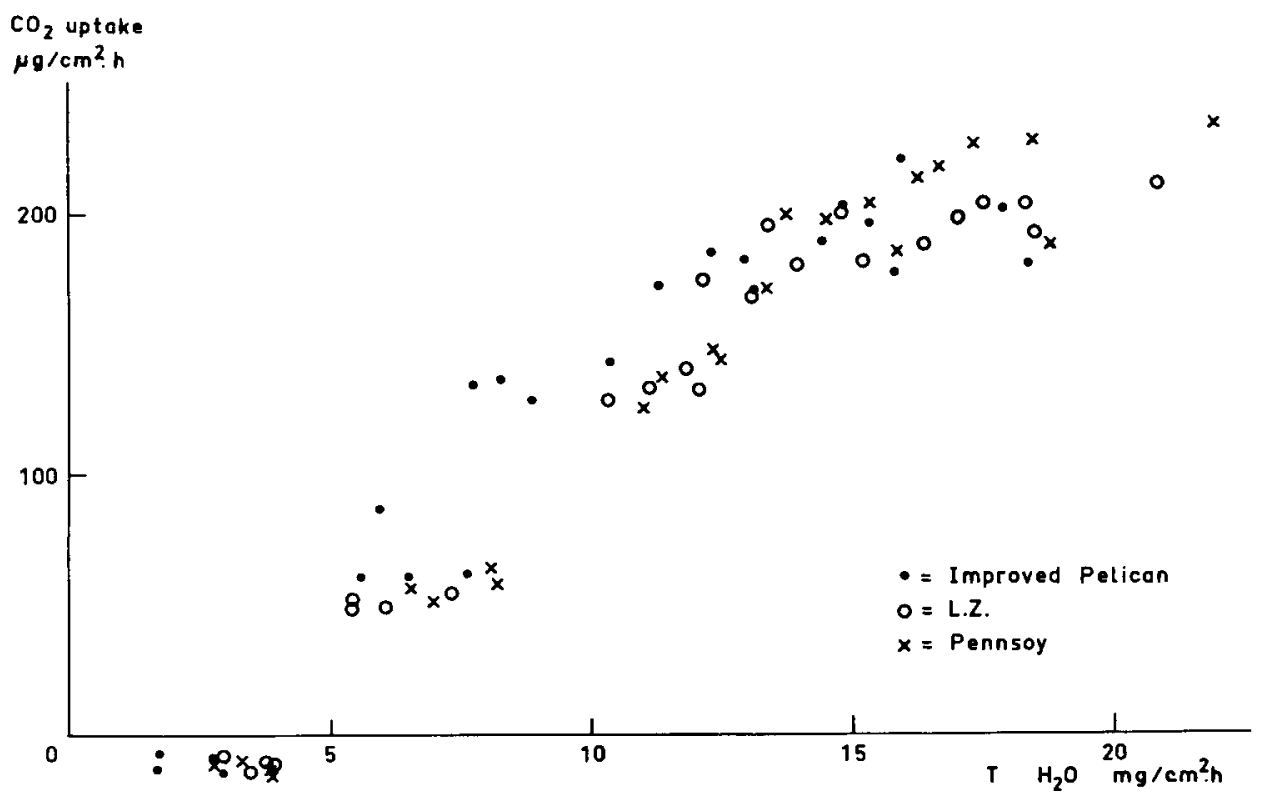

Fig. 5. Photosynthesis rate as a function of transpiration $\left(\mathrm{mg} / \mathrm{cm}^{2}, \mathrm{~h}\right)$.

Differences between varieties and other interactions have not been found $(\mathrm{P} \%>25)$. Water consumption (Table 3 ) shows a positive correlation with day length regime and water supply $(\mathrm{P} \% \leqslant 0.1)$ and a less certain correlation with their interaction $(\mathrm{P} \%$ 1-2.5). Interaction between water supply and variety results in a rather uncertain effect on dry weight ( $\mathrm{P} \% 5-10)$, whereas it is uncertain $(\mathrm{P} \%>25)$ whether variety and its interaction with water supply has any influence.

The relation between dry matter production and water consumption is shown in Fig. 2 for 1968 end in Fig. 3 for 1969.

The rate of photosynthesis in normal air as a function of light intensity determined with plants in solution in fourfold, showed so much similarity for the three varieties that there is no reason to assume that their ability of assimilation is different (Fig. 4).

This also holds for the relationship between photosynthesis rate and transpiration rate (Fig. 5), which was found to be curvilinear in short periods.

\section{Discussion}

Under the prevailing photoperiod (about 16 hours of day length at the beginning of the experiment and about 12 hours at the end of it), the soybean varieties did not produce flowers.

The same results were obtained by Hammer (1940), Blaney and Hammer (1957), Howell (1960) and Hashinoto et al. (1962) in trials with soybean varieties.

The rectilinear relation between production of dry matter and transpiration stated by de Wit (1958) in different crops was confirmed for the three soybean varieties, transpiration being identical with water consumption in the experiment. The negative con- 
stant in the regression equations may be due to the relatively too high values of water loss of the driest treatment (Fig. 2). Since the number of waterings was the same for all the pots the smallest quantities suffered relatively greater losses on the surface of the small pebbles than the greater quantities. A similar observation was made by Jensen (1968). The negative constant may also be partly due to the fact that roots were not harvested.

The slope of the line is different for plants under the prevailing day length and the controlled one. This applies to each variety in 1968 (Fig. 2) as well as in 1969 (Fig. 3), when $\mathrm{P} \%$ was $\leqslant 0.1$. Rather than in terms of transpiration a more likely explanation of the difference in slope of both photoperiods seems to be in terms of photosynthesis, which was stopped during a number of hours each day in the plants under controlled day length. Transpiration could hardly have increased inside the curtains, though in 1969 small fans were placed above the plants inside the shielding curtains to prevent the temperature within from rising and thus increasing respiration. The considerable variation, especially in the results of 1968 , and the different arrangement of the experiment are reasons not to try to explain the difference in slope of the lines of each daylight regime in both years.

The rate of photosynthesis is somewhat lower than the average rate of a number of agricultural plant species as shown by a curve of de Wit (1966). The average rate of about $200 \mu \mathrm{g} \mathrm{CO} / \mathrm{cm}^{2} . \mathrm{h}$ at light saturation determined for rectangular exposition is the same as the mean daily rate for an average $\mathrm{cm}^{2}$ of normally exposed leaf in a canopy on a field at Urbana, Ill., measured for the variety Wayne (Egli et al., 1970).

The highest production of dry matter (about $80 \mathrm{~g} / \mathrm{plant}$ ) in 1968 was much greater than that in 1969 (about $35 \mathrm{~g} / \mathrm{plant}$ ). This was caused by the different water treatment of the wettest pots: an unlimited water supply in 1968, and a periodical application of a standard amount of water in 1969 , which was still far from being liberal. The ratio $\mathrm{DM} / \mathrm{W}$ was correspondingly different: on the average about $2.1 \mathrm{~g}$ dry matter per $\mathrm{kg}$ water with liberal water in 1968 and about $2.5 \mathrm{~g} / \mathrm{kg}$ with limited water in 1969 .

\section{Conclusions}

1. Differences between the varieties 'Improved Pelican', 'L.Z.' and 'Pennsoy' in respect to dry matter production, seed production, water consumption and rate of photosynthesis are not significant (Table 1, 2 and 3).

2 . There is a rectilinear relationship between seed production and dry matter production, and between dry matter production and water consumption (Fig. 1, 2 and 3).

3. In controlled day length productivity per unit of water consumption is smaller than in prevailing day length (Fig. 2 and 3).

4. The rate of photosynthesis is somewhat lower than the rate presented by de Wit for most agricultural crops (Fig. 4).

5. The relationship between rate of photosynthesis and transpiration rate is curvilinear (Fig. 5) for short periods.

\section{Acknowledgments}

Thanks are due to Mr H. D. J. van Heemst, Mr C. A. Hoveyn and staff, and to Miss A. H. van Rossem. 


\section{References}

Blaney, L. T. \& K. C. Hammer, 1957. Interrelations among effects of temperature, photoperiod, and dark period on floral initiation of Biloxi Soybean. Bot. Gaz. 119 (1): 10-24.

Egli, D. B., J. W. Pendleton \& D. B. Peters, 1970. Photosynthetic rate of three soybean communities as related to carbon dioxide levels and solar radiation. Agron. J. 62 (3) 411-414.

Hammer, K. C., 1940. Interrelation of light and darkness in photoperiodic induction. Bot. Gaz. 101: $658-687$.

Hashinoto, T., S. Kumano \& K. Saito, 1962. Growth habit of Soybean varieties sown through the year with special regard to the relationship between flowering, maturing and temperature, day length. Bull. Hokuriku agric. Exp. Stn 3: 97-115.

Howell, R. W., 1960. Physiology of the soyabean. Adv. Agron. 12: 265-310.

Jensen, M. E., 1968. Water consumption by agricultural plants. In: T. T. Koslowski, Water deficits and plant growth, Vol. II : 2-22.

Louwerse, W. \& J. L. P. van Oorschot, 1969. An assembly for routine measurements of photosynthesis, respiration and transpiration of intact plants under controlled conditions. Photosynthetica 3 (3) 305-315.

Oorschot, J. L. P. van \& M. Belksma, 1961. An assembly for the continuous recording of $\mathrm{CO}_{2}$ exchange and transpiration of whole plants. Weed Res. 1: 245-257.

Wit, C. T. de, 1958. Transpiration and crop yield. Versl. Landbouwk. Onderz. 64.6; pp. 88.

Wit, C. T. de, 1966. Photosynthesis of crop surfaces. Adv. Sci. 23: 159-162. 